\title{
Understanding and Predicting Customer Choices
}

\author{
Rohit Verma
}

Your customers are confronted with multiple options for where they can dine and where they will stay for the night. The choices they make among the many lodging and dining options are based on criteria that are not always clear-certainly not to you, and often not to them. Your guests may have chosen your hotel because of its favorable room rate, its brand name, its quality rating, its features and amenities, reviews posted by past guests on social media sites, or simply because they were ready to stop for the night and there it was. Similarly, in the case of a restaurant, a customer's choice may be influenced by the cuisine, menu, décor, price, and reputation.

The more you can learn about what factors your guests take into account when they decide whether to book your hotel or a competitor's property, the better you are able to meet those decision criteria and boost occupancy and rate. In this chapter, I explain two ways to find out those criteria: simply ask, or set up discrete choice experiments. The reason for the experiments is that when you simply ask, you might not get an accurate or complete answer. The problem with the experiments is that the procedure can be complicated, even though the information itself is most useful.

\section{Asking about Decision Factors}

Let's look at a study where we just asked people what web-page factors were most important to them. Table 7.1 shows the results of this survey, in which hotel customers were asked to rate the relative importance of various features of the hotel when they search for hotel information on travel-related Web sites. The results presented here show the different weights assigned to various characteristics of a hotel Web site, and we see that there are considerable differences between subgroups of customers based on age and gender in terms of how they assign weight to various hotel web features.

We can guess that a hotel's features and amenities are important, not only on the web page but in terms of booking the hotels, since those were highly ranked in this survey. But this survey didn't touch on the question of rate, so we must look further.

While it is useful to note the importance of different criteria in this way, your customers are also considering value when they book a stay at your hotel or a meal in your restaurant. They consider all these criteria simultaneously, including different possible values relating to price (e.g., low, medium, or high) and quality (e.g., 2-, 3-, or 4-star rating). Therefore, each option (e.g., hotel) represents one combination, or a bundle, of many different decision 
variables.

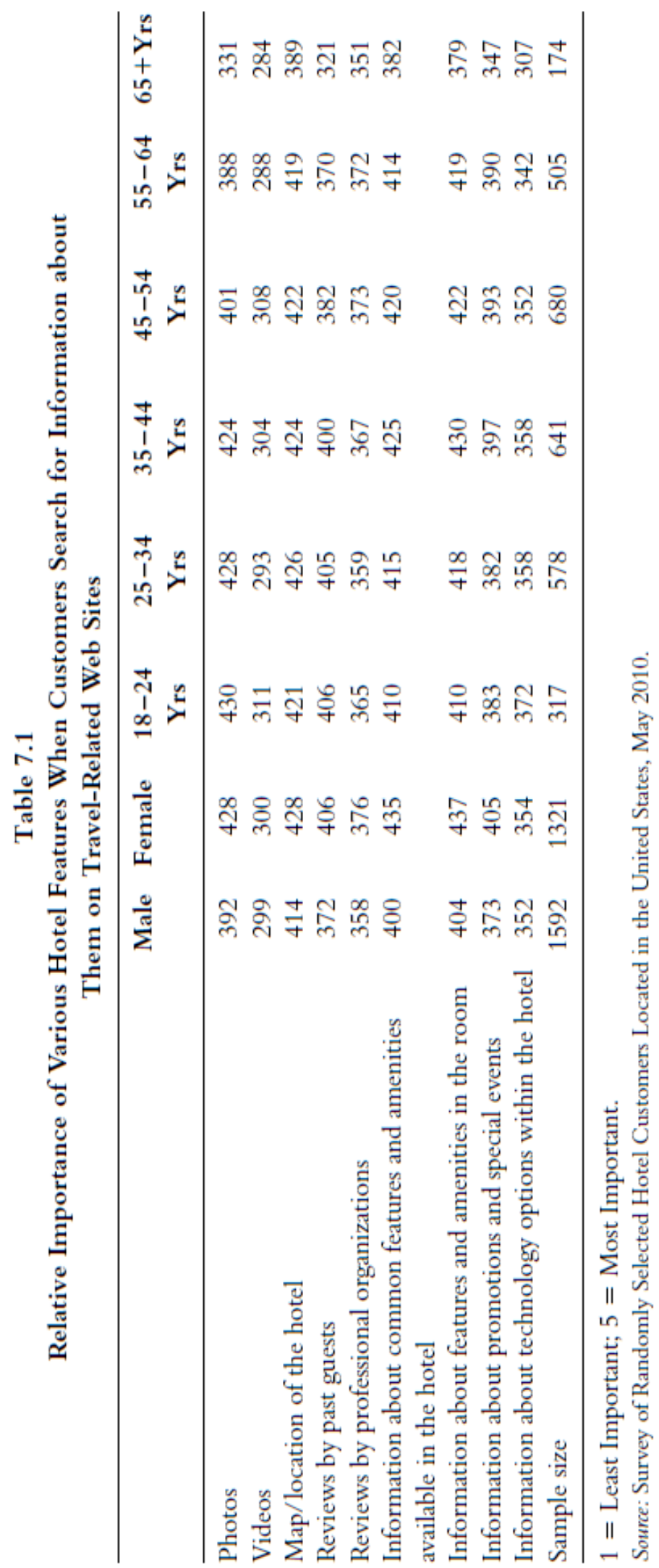




\section{$\underline{\text { Hotel Decision Criteria }}$}

Let's take as an example, the Statler Hotel, which is operated by the School of Hotel Administration as a fully commercial teaching hotel. It's located in Ithaca, New York, right on the beautiful campus of Cornell University. Ithaca is a relatively small market that often sells out on busy weekends (such as homecoming and graduation). If you wanted to reserve a room at the Statler during one of the upcoming busy weekends, you might consider a bundle of benefits such as the one displayed in Figure 7.1. Several fi ne hotels are located within three miles of the campus, including those shown in Figure 7.2. Thus, assuming the Statler has availabilities, the decision by a customer to stay there will be influenced not only by the Statler's package of benefits, but by those offered by other nearby hotels. Now the customer has to make a choice: she can either choose to stay at one of the three hotels presented so far, or explore additional options.

As I said, Ithaca is a small market, but it has several other hotels (and there are many more in nearby towns). In a major market, the lodging possibilities are nearly endless. Thus, you can see the complexities involved in the customer choice process. This is why simply asking the customer why she booked a hotel doesn't always work. There are too many trade-offs.

In reality, the problem of determining customers' preferences is even more complex than the example we gave because we were considering only one customer. But there are many customers, of course, and the customer base for hospitality companies is becoming ever more diverse (e.g., business and leisure travelers; customers with different ethnicities and cultures; customers with different views of technology). Therefore, you need to develop a clear understanding of customer choice patterns for each market segment, so that you can properly configure your property's offerings for profitability and success.

\section{Figure 7.1}

\section{Statler Hotel (Ithaca, NY) on Expedia}

\begin{tabular}{|c|c|c|c|c|}
\hline 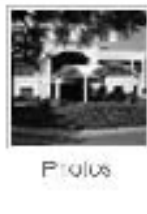 & 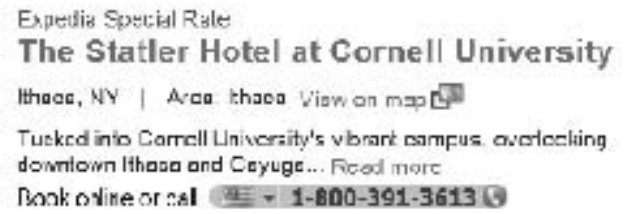 & 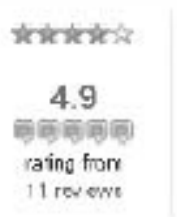 & \multicolumn{2}{|c|}{$\begin{array}{l}\$ 220 \\
\text { dyy iigtl }\end{array}$} \\
\hline \multicolumn{2}{|l|}{ Rcom ton= } & Sat & \multicolumn{2}{|c|}{ Avuret niont } \\
\hline \multicolumn{2}{|c|}{$\begin{array}{l}\text { Tradtional couble } \\
\text { Intludes: Free Hah-Speed Intemet, Free Airport Shuttle }\end{array}$} & $\$ 220$ & $\$ 220.00$ & Bo=k it ? \\
\hline \multicolumn{2}{|c|}{$\begin{array}{l}\text { 3uperior View King } \\
\text { Inclules: Free High-Speed intemet. Free Airport Mutule }\end{array}$} & $\$ 230$ & $\$ 260.00$ & Bo:k il \\
\hline \multicolumn{2}{|c|}{$\begin{array}{l}\text { Suseriar Vhew Douzles } \\
\text { inclutos: Froo High-6pood Intornot, Froo Airport Shuttlo }\end{array}$} & maso & $\$ 2600$ & notk it \\
\hline
\end{tabular}


Figure 7.2

Two Additional Hotel Listings on Expedia for Ithaca, NY

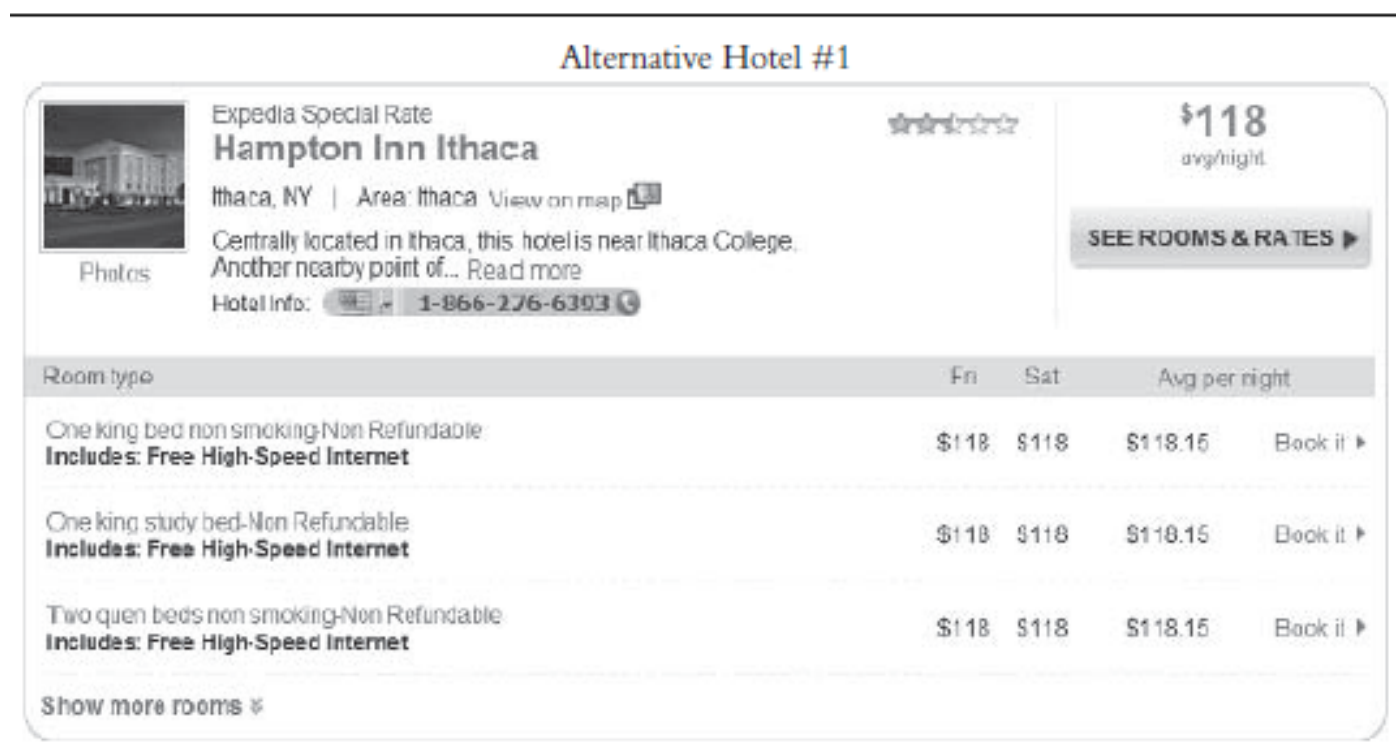

Alternative Hotel \#2

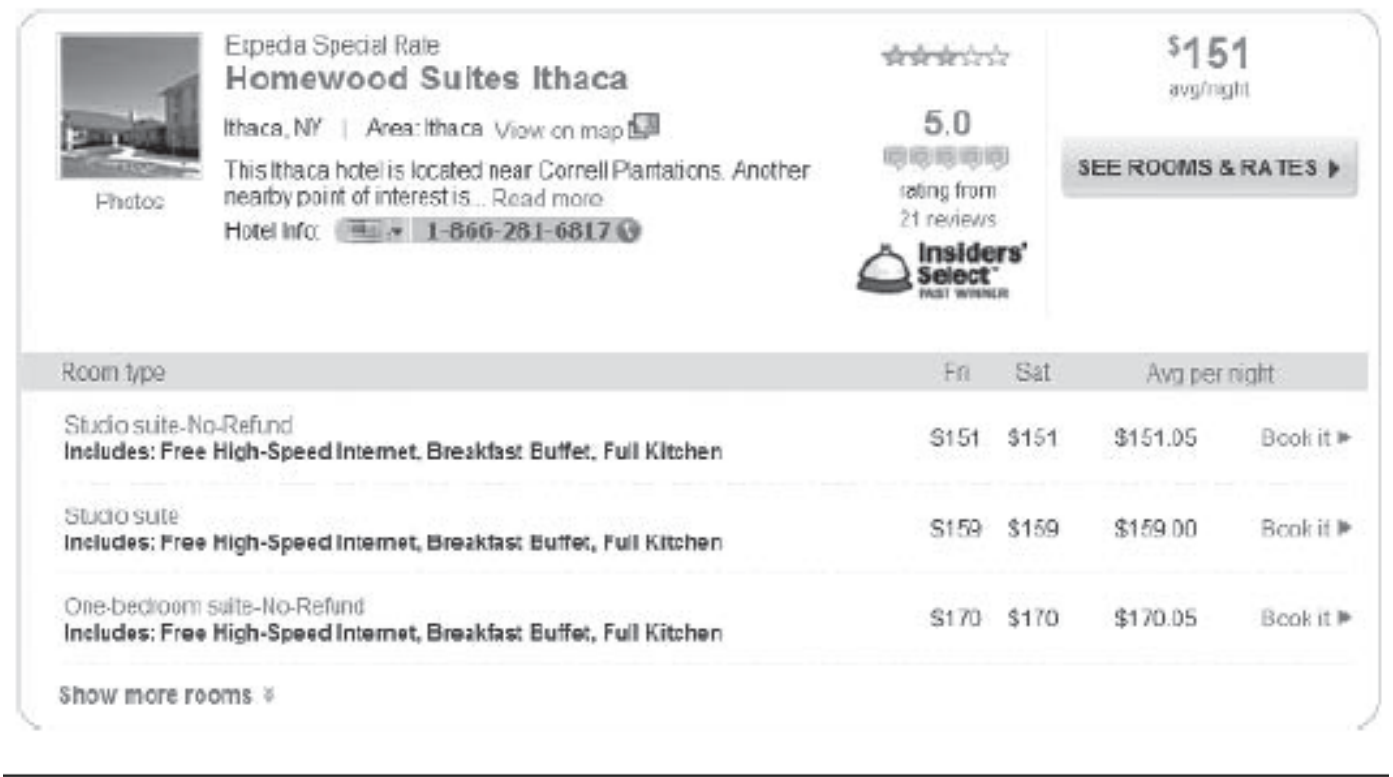

Without a clear understanding of customer choices, firms often play "spray and pray" games with their offerings. They send up multiple offers in the hope that at least one will stick! As a result, markets often are flooded with goods and services that have relatively little actual value or significance for customers. Your guests may chow down on your complimentary breakfast, for instance, but do you know for sure that this was a factor that drove their booking decision? Furthermore, firms face complex problems of what to combine when deciding which goods-and-services bundles to offer in the marketplace. Given the many potential combinations 
of offerings, a simple "gut feel" to decide what might be of interest to customers is not sufficient in a competitive hospitality marketplace. There's no doubt that "informed guessing" might lead to new and innovative ideas; however, it might also lead to "managerial pet projects," causing depleted profits and severe heartaches!

In summary, understanding customer choices is a key to successful management of hospitality businesses. At the same time, predicting customer choices for competitive markets is complex and therefore requires a more scientific approach than simple rules of thumb. As described in the rest of this chapter, an excellent approach for doing this is known as discrete choice analysis (DCA). DCA has been found to be effective in predicting customer choices in a wide range of industries. Chapter 24 explains Marriott's use of DCA in developing the Courtyard brand, for instance. Additional examples of applications of discrete choice analyses in the hospitality industry are presented in Table 7.2. The ideas presented in this chapter will help you in expanding your understanding about how to scientifically predict customer choices.

Table 7.2

Articles Based on Customer Choice Modeling Published in Cornell Hospitality Quarterly and Cornell Hospitality Report

- R. Verma and G. Thompson, "Basing Service Management on Customer Determinants: The Importance of Hot Pizza," Comell Hotel and Restaurant Administration Quarterly 37 (1995): 18-23. This article explains the basics of discrete choice analysis through a study of how customers chose a pizza-delivery company by trading off among several attributes (price, discount, promised delivery time, late-delivery time, variety, temperature, and money-back guarantee). The article further describes how the results of such a discrete-choice analysis can be incorporated into a decision-support system via a computer spreadsheet.

- R. Verma, M. Pullman, and J. Goodale, "Designing and Positioning Food Services for Multicultural Markets" Cornell Hotel and Restaurant Administration Quarterly 40 (1999): 76-87.

A discrete choice analysis based study compares the food-service preferences of individuals from three different language groups (English, Japanese, and Spanish). All three groups of respondents were relatively price insensitive for the four different types of restaurants studied and often were willing to wait either to order or to be served, depending on the food-service concept (e.g., waiting for pizza made sense to them, but waiting for burgers did not). Many respondents liked the idea of pictures of the food on menus to help identify unfamiliar items, but virtually no one wanted menus translated into their native languages. Based on the study, one food-service outlet adopted a new marketing strategy that not only increased its market share but attracted more patrons to the food court.

- R. Verma, G. Plaschka, and J. Louviere, "Understanding Customer Choices: A Key to Successful Management of Hospitality Services," Cornell Hotel and Restaurant Administration Quarterly 43 (2002): 15-24. 
This article describes in considerable detail how many different managerial decisions can be derived more effectively by using customer choice modeling techniques. The article describes how the results can be used to identify the preferences of customers in different market segments, calculate market share, identify order winners and qualities; calculate brand equity; calculate switching barrier; and develop implementation guidelines.

- J. Goodale, R. Verma, and M. Pullman, "A Market-utility Approach to Scheduling Employees," Cornell Hotel and Restaurant Administration Quarterly 44 (2003): 61-69.

This article describes how the results of a carefully planned choice experiment can be used to develop effective labor schedules. The paper first discusses the components that make up this approach, which includes methods from customer-preferences modeling, service-capacity planning, and the four tasks of labor scheduling. Next, it is shown how the model applies to balancing queue lengths and operating costs for an airport food-court vendor.

- R. Verma and G. Plaschka, "Customer-Choice Modeling: Reflections, Advances, and Managerial Implications," Cornell Hotel and Restaurant Administration Quarterly 44 (2003): 156-165.

This essay attempts to highlight some of the valuable managerial and methodological insights on customer-choice modeling observed over the course of the past ten years. To make this essay useful to both managers and academic researchers, it discusses thoughts on CCM in the context of methodological advances and managerial applications in service-driven markets. Choice modeling can yield valuable insights for market-driven strategy development by revealing customer clusters, suggesting the potential effects of changing the levels of value drivers, assessing overall brand equity, and identifying customers' switching barriers.

- R. Verma, "Unlocking the Secrets of Customers' Choices," Comell Hospitality Report 7(2) (2007).

This report describes how customer willingness to pay and desirability can be calculated from the results of a customer choice modeling study. The report includes a spreadsheet template that allows readers to manipulate customer choice modeling data and calculate willingness to pay and desirability for a hotel and restaurant context.

- Dixon, Kimes, and R. Verma, "Customer Preferences for Restaurant Technology Innovations" Cornell Hospitality Report 9(7) (2009).

This report presents the results of a national survey on customers' perceptions of eleven restaurant technologies, as well as whether respondents use those technologies and the value they see in them. Using a research technique called best-worst choice analysis, the study found that the technologies used most commonly were pagers and online reservations, while cell-phone payment was used hardly at all. The results show that the perceived value of a specific technology increases after the customers have had the opportunity to use it, and different demographic segments valued the technologies differently.

- Taylor and R. Verma, "Customer Preferences for Restaurant Brands, Cuisine, and Food Court Configurations in Shopping Centers," Cornell Hospitality Report 10(3) (2010).

An analysis of the mall restaurant preferences of a national sample of 1,737 U.S. residents sheds light on how to configure mall food service and demonstrates how local malls can determine what their particular market desires. Using customer choice analysis, this study asked respondents to choose among six mall food-service configurations, including one that had a large food court and one that had no food court at all. The most popular configuration combined a moderate-size food court with several casual and fast-casual restaurants. Least popular was the choice that had only table-service restaurants and no food court. 


\section{Assessing Customer Choices}

The initial ideas for DCA were introduced by Professor Daniel McFadden, Nobel laureate in Economics in 2000. By combining McFadden's framework with experimental methods developed by Professor Jordan Louviere and several other researchers, we can gain valuable insights about how customers choose goods and services in the hospitality industry. DCA comprises the following steps: (1) identify choice criteria, (2) develop choice experiments, and (3) collect responses and estimate choice models. With those data in hand, you can conduct extensive analyses using decision support systems.

\section{Step 1: Identity Choice Criteria}

Before trying to predict future customer choices, one must first understand the list of criteria customers use in their choice processes. As in the relatively simple case of hotels in the Ithaca region, customers consider multiple criteria when making their choices, and you can use DCA to identify them. In Ithaca, the main criterion might be how close you are to the campus, or at least how easy it is to get there. But another criterion might be that customers want to be in walking distance of food and beverage outlets, which argues for the set of hotels that are downtown, or the suburban properties adjacent to the malls.

You can develop a list of these potential criteria by using qualitative market assessment approaches, such as expert interviews, customer focus groups, case studies, macro- and microeconomic industry data, and other data-rich information sources (e.g., blogs, social media chatter). From these, you can develop a list of purchase attributes that you believe are influencing customer choices. For a hotel the choice criteria may include type of hotel (e.g., motel, bed-and-breakfast inn, boutique hotel, convention hotel), star rating, average past guest review, price, loyalty program, in-room amenities, or recreation options. Table 7.3 lists some of the potential criteria for selection of a restaurant and a hotel.

\section{Step 2: Develop Choice Experiments}

After you identify the criteria that probably influence your customers' choices, you need to develop the possible realistic levels for each of these potential decision factors. For example, you may consider the following options for loyalty program: none; one point per dollar spent; two points per dollar spent; or three points per dollar spent. For in-room amenities, you may consider offering different types of TVs; various levels of bathroom amenities, or the presence or absence of a kitchenette. Similarly, as recreation options within the hotel, you may consider an indoor or outdoor swimming pool; tennis courts; or a golf course.

As you probably have guessed, such lists of hotel choice criteria can become quite lengthy. So before you start surveying consumers, you will have to critically assess the relevance of each criterion in customers' choice processes. For example, you don't have much control over such characteristics as your location or your floor plan. However, you probably do control certain aspects of the property, such as the type of restaurants located on-property, 
whether you offer a complimentary breakfast, and the extent of room amenities. Therefore, you need to strike a balance between the complexity of choice criteria and the reality of a survey, including its cost and benefit.

After identifying the relevant choice criteria, your next step is to construct several realistic scenarios based on different values of each of the choice criteria identified. A simple example of a hotel choice experiment is presented in Table 7.4. Within the customer choice experiments, respondents are asked to "choose" or "not to choose" among alternatives presented in "choice sets." Each choice set can contain various explicit market offerings based on identified market choice drivers and their value extensions. For a customer choice assessment study in the hospitality industry, you might describe two hotels in a choice set, each with a number of market drivers and specific value extensions for each. So, for a hotel in Ithaca, you might have as a value driver its distance from campus, and the value extensions might be on or walkably adjacent to campus, three miles (or less) from campus, more than three miles from campus. Depending on the objective of the study, you can ask your questions in various formats. One way to do this is to show the respondents lists like those in Table 7.4 and ask, "If these two hotels were your only alternatives, which one would you choose-Hotel 1 or Hotel 2

Table 7.4

Sample Choice Experiment for the Choice of a Hotel

\begin{tabular}{lll}
\hline & Hotel 1 & Hotel 2 \\
\hline Room Rate & $\$ 100$ & $\$ 135$ \\
Brand Name & National brand & Independent hotel \\
Star Rating & 2.5 -star & 3 -star \\
Loyalty Program & 1 point $/ \$$ spent & None \\
Recreation options & Indoor swimming pool & Spa and tennis courts \\
$\ldots$ & $\ldots$ & $\ldots$ \\
\hline
\end{tabular}

Some options for choice questions:

A. If the above two hotels were your only alternatives, which one will you choose: Hotel 1 Hotel 2 Neither

B1. If Hotel 1 was your only option, would you stay there?

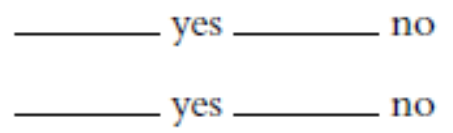

B2. If Hotel 2 was your only option, would you stay there? yes no

C. List the most attractive and least attractive features of the two hotels: Hotel 1 most attractive feature least attractive feature Hotel 2 most attractive feature least attractive feature

or neither?" You could also ask: "If Hotel 1 were your only other option, would you go there during your next trip or stay at your previous hotel?" Yet another approach is known as a most- 
least attractive analysis, based on this question: "What do you consider the most and least attractive features of each hotel?" These approaches are spelled out in Table 7.4.

Even just a few years ago, a typical choice experiment involved lengthy printed survey forms that used a series of preconfigured, table-like formatted choice scenarios (like the sample in Table 7.4). Although the experiments were solid, the choice sets were presented as static tables with little room for customization to identify the purchase drivers that most interested the respondents. Information technology has made this type of experiment much more effective, because we can use digital imaging and streaming video technologies, almost unlimited computing resources to customize questionnaires, and sophisticated programming languages that allow you to develop realistic and highly customizable choice experiments specific to each respondent. These choice experiments are visually appealing and employ easyto-use formats, resulting in a high level of respondent involvement.

For example, in our recent studies, we have extensively used web-based technologies to realistically illustrate choice scenarios for our hospitality respondents (with hyperlinked pictures or written illustrations, brand logos, and audio and video fi les). In one study, we showed professional actors demonstrating several different service scripts in face-to-face customer interactions at a hotel front desk. The video clips of the service scripts along with other features of the service interactions were presented to the customers in the form of a discrete choice experiment to gauge what kind of interaction they preferred at the front desk. In another study, in a retail setting, we showed respondents a series of screens, each with several pictures and detailed descriptions, to depict the customer service, shopping experience, and parking convenience at a futuristic shopping center. Later, when the respondents were presented with the actual discrete choice exercise, the earlier descriptions were available as hyperlinks for ready reference.

When choice experiments require transferring huge amount of data, you can give respondents high-capacity portable storage devices (e.g., USB storage keys) or take along a laptop when you conduct the interview. Although such options have been available for some time, they have only recently become relatively cost effective and easy to implement. Someday, three dimensional virtual reality technologies will become inexpensively available to create truly realistic choice experiments. Some early indications of the use of such technologies in limited fashion exist (e.g., the launch of a prototype W Hotel in the virtual reality world SecondLife.Com).

\section{Step 3: Collect Responses and Estimate Choice Models}

Once you've designed your choice experiments, the next step is to collect responses from a representative sample of customers (or potential customers). To do the study, you show each respondent several choice scenarios and ask each person to register their single choice among the available options (including no choice). As they choose, your respondents gradually build a profile of their decision criteria, including the most desirable, least desirable, and 
indifferent product features. Usually, you would develop statistical models that predict customer choice for this purpose. These statistical models calculate relative weights that customers explicitly or implicitly assign to different choice criteria. Once the weights are identified, you can select the optimal combination of choice criteria to develop a more profitable and sustainable value proposition.

While the estimation of choice models requires advanced statistical knowledge, you can use a decision support system (DSS) to implement the results. Using a DSS, you can perform various managerial "what if" analyses and predict future customer choices.

\section{Managerial Insights from Discrete Choice Modeling}

Although you may want to engage professional assistance in developing your DCA experiment, once you have the data, you will be in a position to develop the insights and strategies that are suggested by the resulting information. In a series of articles, my coauthors and I have described a number of managerial insights that have emerged from customer choice modeling studies. ${ }^{1}$ Let's look at some of the valuable managerial implications that have arisen from these studies.

As I said, the statistical models developed from customer choice studies can be easily incorporated into decision support systems (Figure 7.3). While design of customer choice experiments and estimation of models requires sophisticated training and skills, implementation of the estimated model(s) can be handled on a DSS spreadsheet. Once the DSS is available, you can input the attributes of your own product and that of your competitors to predict expected market shares. The DSS essentially approximates the dynamic nature of the market, allowing managers to evaluate multiple businesses, operating and marketing strategies, and the effects of changing strategies in the competitive marketplace. In addition, the predictive power of customer choice models can be further improved by market segmentation techniques.

Figure 7.3

Types of Decision Support Models Based on Discrete Choice Analysis

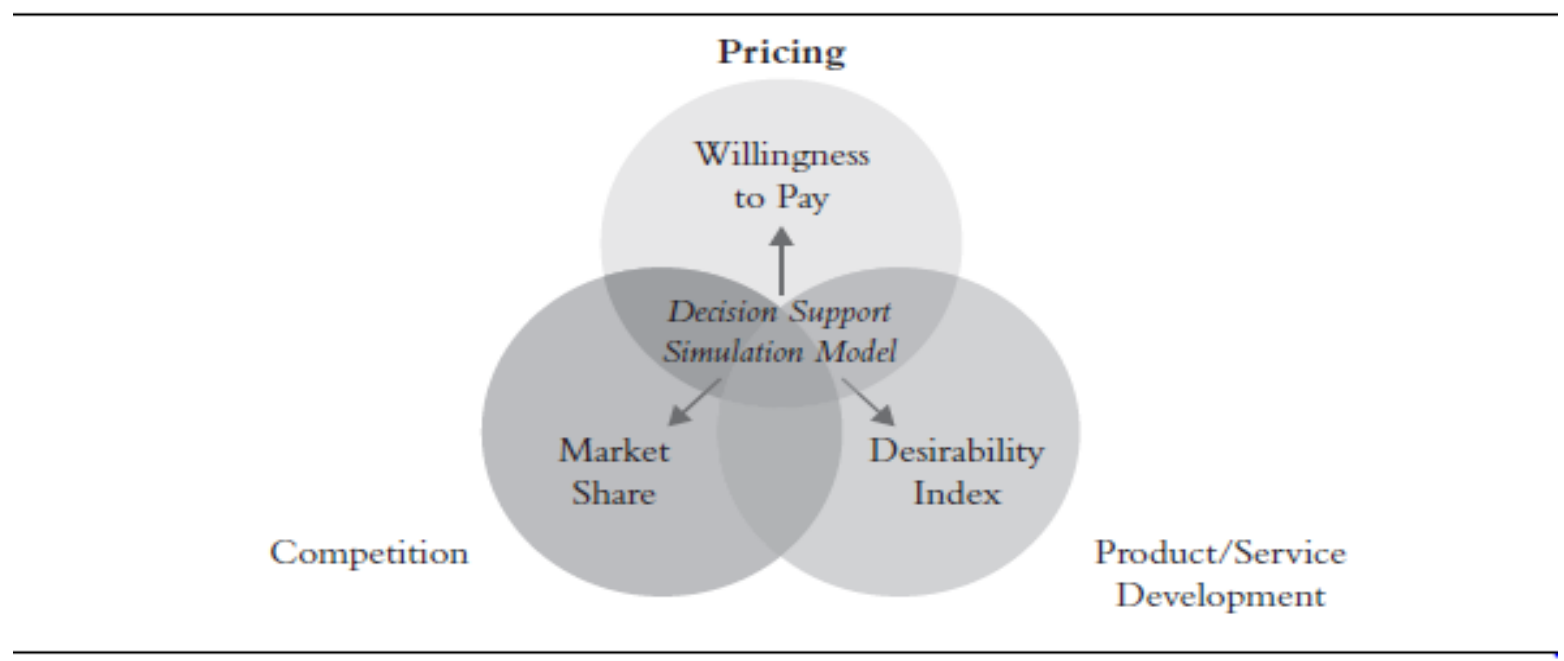


The relative weights of various choice criteria can be used to identify the decision criteria that your customers have in common, and you can assess how these popular product attributes will influence the current and future value of your hotel's offerings. The choice models can also identify key features that drive market share in different customer preference clusters. As I explained in a 2007 article, you can develop clusters of customers based on their preference, and you can even give them fanciful descriptive names. ${ }^{2}$ In that article, I labeled different customer preference clusters as Gourmet Buyers, Tough Sells, and Bargain Hunters. Then I could calculate the relative utilities (or value) of various choice drivers for each of those customer clusters (e.g., price, brand name, feature, service). So, for instance, the Gourmet Buyers found relatively high value in the brand name, feature, and service attributes, but not on price. The Tough Sells considered all four of those choice drivers to be relatively equal in importance, whereas the Bargain Hunters seemed to be the most price sensitive (as you might guess). Identifying such preference differences across customer groups can help you develop a more effective marketing campaign for each cluster.

Here's another example of the kind of analysis you can do once you have the DCA information. With my colleague Gary Thompson, I studied the decision factors for a pizzadelivery company. ${ }^{3}$ We observed how the customers traded off among various attributes (at least on our selection cards). Those factors were price, discount, promised delivery time, late delivery time, variety, temperature, and money-back guarantee. We discovered that a particular decision point was delivery temperature-in short, people liked their pizza to arrive hot and steaming. Without this kind of analysis, you might be forced to guess what made people choose one company over another-and a wrong guess might cost you money spent on unnecessary product features.

"What If" Analyses The relative importance weights for each decision factor can be used to develop two useful "what-if" analyses for combinations of service offerings, namely customer desirability and willingness-to-pay. The desirability can be presented in the format of a relative index between zero and 100 . Calculated this way, a desirability index of zero represents the least desirable service of all possible combinations. Similarly, a desirability index of 100 represents the most desirable service combination. The willingness-to-pay analysis for a specific market offering is just what it sounds like-an index of the price customers are willing to pay for a particular product feature, if they desire it. Generally speaking, if we know a product's relative utilities (i.e., the value assigned to different product attributes), consumers' propensity to choose a particular product, and the desirability of that product, we can calculate willingness to pay. The hotel industry calculations can be confused by the "noise" created by ever-shifting room rates. Nevertheless, it's possible to get a sense of customers' willingness to pay by grouping hotels into price ranges (such as economy, midscale, and upscale). You can download a complete explanation and application of these ideas from the Cornell Center for Hospitality Research (chr.cornell.edu). In these publications, all available at no charge, you will find the report called "Unlocking the Secrets of Customer Choice." ${ }^{4}$ Or you can search for my name (Verma) and see a list of several reports that I have written on this topic. 
In addition to identifying the overall relative impact of customer preferences, choice modeling results can also be used to assess the relative impact on market share of changing the value of one or more variables. For example, the models can predict how your market share might be affected if one of your competitors makes a change in one or more choice drivers. With this analysis you can focus on a selected few choice criteria as you consider developing new products or services or changing selected features of existing offerings.

Assessment of brand equity (as related to customer choices) is another potentially important analysis that you can conduct once you have the choice modeling results. I also believe that robust and reliable estimates of switching inertia can be easily derived by designing customer choice experiments that ask respondents to choose between "current" and "new" service providers. This kind of analysis will give you a sense of what keeps guests returning to your hotel (switching barriers or inertia) despite the availability of other, "better" offerings. At the same time, it will also give you a sense of what might happen if a new service provider in fact overcomes existing customer inertia by offering a substantially stronger service bundle or by customizing its service bundle to gain dominance in a market.

Customer choice modeling results can also be used for developing effective implementation guidelines or for prioritizing various initiatives so as to maximize the net gain from any chosen strategic plan. By understanding consumer choices, you can effectively develop and position service offerings to better suit your market's needs. In addition, mathematical models representing consumer choice can be linked to several operating decisions (e.g., labor scheduling, special activities planning, service offerings), and optimal service configurations can be identified for further improvement.

In addition to the applications previously described, choice models and associated DSSs also can be used as education and training tools and to help managers better align their decisions with what customers want and are willing to pay for. If you feel that you are too distracted by day-to-day operations, you can get back in touch with your customers' actual needs by examining DCA results. As a test exercise, you might try comparing two choice models: one representing customer choices and another one representing managers' beliefs about customer choices.

While DCA does require some heavy-duty statistical analysis, that is not out of reach. Once you have the data from a well-designed DCA study, you can begin predicting customer choices. For a hospitality firm to be successful, I believe that a sophisticated customer choice approach is essential. If you make DCA an essential component of your managerial decisionmaking framework, you will have a far more accurate ability to predict market share, your customers' willingness to pay, and how desirable they consider your hospitality services.

\section{Notes}

1. For example, R. Verma, G. Plaschka, and J. Louviere, "Understanding Customer Choices: A Key to Successful Management of Hospitality Services," Cornell Hotel and Restaurant 
Administration Quarterly 43 (2002): 15-24; R. Verma and G. Plaschka, "CustomerChoice Modeling: Reflections, Advances, and Managerial Implications," Cornell Hotel and Restaurant Administration Quarterly 44 (2003): 156-165; and R. Verma,

"Unlocking the Secrets of Customers' Choices," Cornell Hospitality Report 7(2) (2007).

2. Verma. 2007

3. R. Verma and G. Thompson, "Basing Service Management on Customer Determinants: The Importance of Hot Pizza, Cornell Hotel and Restaurant Administration Quarterly 37 (1996): 18-23.

4. Verma, 2007. 